Meta

Journal des traducteurs

Translators' Journal

\title{
Quantum Mechanics and the Theory of Poetry Translation
}

\section{Grigori M. Kružkov}

Volume 37, numéro 1, mars 1992

La traduction en Russie : théorie et pratique / Translation in Russia: Theory and Practice

URI : https://id.erudit.org/iderudit/003356ar

DOI : https://doi.org/10.7202/003356ar

Aller au sommaire du numéro

Éditeur(s)

Les Presses de l'Université de Montréal

ISSN

0026-0452 (imprimé)

1492-1421 (numérique)

Découvrir la revue

Citer cet article

Kružkov, G. M. (1992). Quantum Mechanics and the Theory of Poetry

Translation. Meta, 37(1), 59-66. https://doi.org/10.7202/003356ar

\section{Résumé de l'article}

On montre qu'il est possible d'appliquer certaines théories de la physique moderne au processus traductionnel. On explique comment les lois de la conservation, la relation d'incertitude, la théorie de la relativité et les formules de Lorentz peuvent s'appliquer à la traduction poétique. 


\section{QUANTUM MECHANICS AND THE THEORY OF POETRY TRANSLATION}

GRIGORI M. KRUŽKOV Poet and translator

Résumé

On montre qu'il est possible d'appliquer certaines théories de la physique moderne au processus traductionnel. On explique comment les lois de la conservation, la relation d'incertitude, la théorie de la relativité et les formules de Lorentz peuvent s'appliquer à la traduction poétique.

\section{INTRODUCTION}

As I set about trying to "bring remote ideas together" (and what could be more remote than literary translation and physics?) I was not looking for paradoxes. I just looked from a certain angle and the multifarious parallels immediately emerged in a broad picture, into a kind of metaphysical conceit.

"There is something to this" I said to myself and decided to capture the picture in words. Maybe someone can use it! After all, there do exist ambivalent beings for whom both the humanistic and logical or purely scientific approach are equally accessible. No doubt Lewis Carroll, Borgès and Nabokov can be counted among their number as well as some of my worthy contemporaries.

\section{THE BLACK BOX}

Our theme is literary translation, or more precisely, the translation of poetry. Let us look at translation as a process - a process about which absolutely nothing is known, except that we start with the original text " $\mathrm{A}$ " and finish with a translated text " $\mathrm{B}$ ", as illustrated in diagram 1.

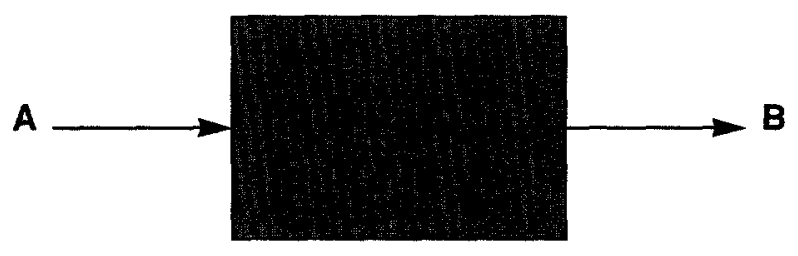

DIAGRAM 1

The sketch represents the classical "black box," the unknown mechanism of transition from $A$ to $B$. The analysis of any process in physics starts exactly in the same way where $A$ is the initial state and $B$ the final state of a physical system. 


\section{THE LAWS OF CONSERVATION}

Let us suppose that the collision of two protons is under consideration. The final state may include other particles since under the right conditions new elementary particles may be formed.

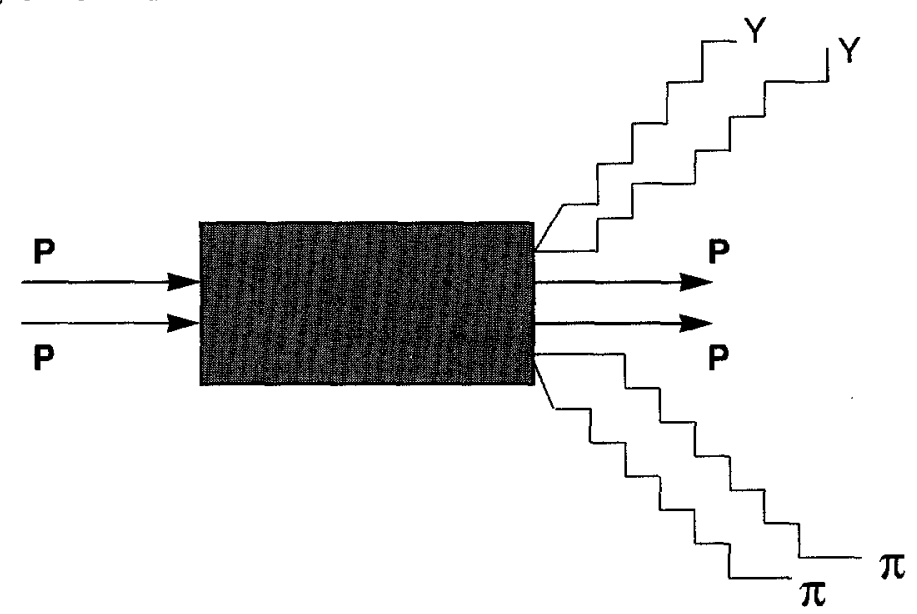

DIAGRAM 2

Once again we encounter a "black box" since a detailed theory of sub-atomic interactions does not yet exist. But does this mean that as long as we lack a theory, we cannot make any reasonable assumptions about the anticipated outcomes of this collision? Or is any final state possible?

Physics answers conclusively: no, not any final state. There are certain general laws to which any transition from A to B must submit itself. These are called the Laws of Conservation and constitute one of the three pillars of modern physics. ${ }^{1}$

Of the Laws of Conservation, two of the most important are the Law of Conservation of Energy and the Conservation of Momentum. Whatever the number of new particles born upon collision, their total energy must be equal to the energy of the two initial protons. Similarly the momentum - in magnitude and direction - must remain unchanged.

These laws were proclaimed by Nature (Her Majesty), All physics did was to understand and incorporate them into theories and formulae.

In translation, it is not a question of natural laws but of laws enforced upon the translator by his craft, or better, his art. And here, once again, we find, that the most important of these are the laws of conservation of energy and momentum!

First of all, it is essential to preserve the energy of the original. Suppose a scathing aphorism, a passionate declaration of love, or words of mourning are rendered in Russian awkwardly and lifelessly, even if semantically correctly. What a difference it makes! Wit falls flat, tenderness becomes insolent and frankness turns into vulgarity. A poor translation verges on a lie - a more profound betrayal is hard to imagine. This is the case a priori. Similarly, a physicist would not even begin to assess the probability of a particular reaction if it is clear that there is not enough energy for it (and hence it is "forbidden").

So much for the law of energy conservation. 
Secondly, in translation, it is essential to preserve the poetical intent of the writer. Clearly it is impossible to retain every single meaning and semantic hue of the original. Once out of flesh, that is, disassembled in the black box, the poem must be reassembled into the substance of another language preserving above all -- what? - its total "momentum" defined as the "resultant" of all the ideas and impulses of the original text ("momentum" means "impulse" in Latin; in Russian "impulse" means "momentum").

Hence the law of conservation of momentum in translation. ${ }^{2}$

Certainly, there are limits to the application of the laws of conservation to translation. First, there inevitably arises a need to correct for inelasticity. Just as in physics where kinetic energy is preserved only in purely elastic collisions, so too in translation, a portion of the energy is usually lost. ${ }^{3}$ The task of the translator is to minimise the loss caused by inelasticity.

Secondly, it is essential to correct for wind factor. The kinetic laws of conversation are also violated when movement occurs in a medium rather than in a vacuum. The internal movements of the medium (not to mention friction) have to be accounted for. Similarly, in translation, the vector of meaning shifts under the influence of such factors as linguistic peculiarities, the translator's particular style, his artistic assumptions. The translator must control the direction of winds and currents "within himself" to avoid excessive drift.

\section{UNCERTAINTY RELATIONSHIPS}

The first - and rather unpleasant - fact which any practitioner of poetry translation encounters is that it is impossible to render all the information contained in the original. The method of compensation seems to be the only acceptable way.

A closer look reveals that any attempt to convey one component of the text too literally leads to the distortion of a second component inextricably connected to the first. It is necessary either to choose or to compromise.

Let us take as an example meaning and sound. If we translate the refrain of Edgar Allan Poe's famous poem:

\section{Bells, bells, bells}

as

"колокола, колокола, колокола"

the tempo and the melody will be hopelessly spoiled.

" $3 \mathrm{BOH}, 3 \mathrm{BOH}, 3 \mathrm{BOH}$ is closer to the original sound (and at the very least, to the original length of the words). But the meaning is still not quite the same. "Бел, бел, бел" or "беc, беc, беc" would be nearly ideal if sound were all we had to worry about, but it would be quite meaningless. In Russian, the most natural choice would be the compromise "звон" (zvon). And of course, we should have to compensate some inadequacies in meaning by other devices.

A further case of the competing elements is well illustrated by the example of two halves of a quatrain. Take Robert Burns:

I bow'd fu'low unto this maid

And thank'd her for her courtesie,

I bow'd fu'low unto this maid

And bade her mak' a bed to me. 
The repetition of the first line in the third produces a rivalry between the second and the fourth. The more accurately we convey the fourth line ("и попросил ее постелить мне постель"), the harder it becomes to convey the second ("и поблагодарил ее за любезность").

S. Marshak was quite right in choosing the fourth line as the line for total accuracy.

Я низко поклонился ей,

Той, что спасла меня в метель,

Учтиво поклонился ей

И попросил постлать постель.

But see how the translation of the second line is far removed from the original. ${ }^{4}$ On the other hand, had he tried to convey the meaning here literally, the meaning of the fourth line would have "run." If the difference in meaning between the original and the translation of line $n$ is represented by $\Delta S_{n}$ the correlation can be portrayed graphically as in the following diagram:

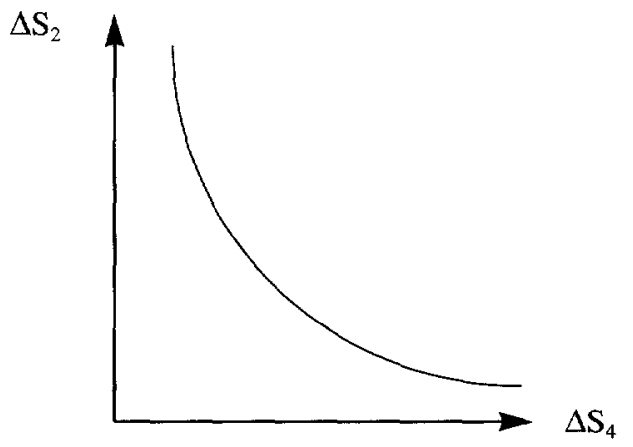

DIAGRAM 3

The curve corresponds to the hyperbolic formula $\Delta S_{2} * \Delta S_{4}=$ const.

Here precisely is the uncertainty relation, so exactly mirroring that found in physics. Let us recall how it is formulated in quantum mechanics. It is impossible to measure the coordinates and the speed of an electron simultaneously. There exist "complementary" quantities, the accuracy in the measurement of which obeys the relations: $\Delta x * \Delta p=$ const.

As we can see, the uncertainty relation comes into play in literary translation too. We discover "complementary" (correlative) components such as the meaning and sound of a particular excerpt of text, or the meaning of two rhyming lines.

The similarity between physics and translation is no mere coincidence and has a mutual origin. Let us remember how the uncertainty relation emerges in physics when the process of measurement is under consideration.

The measuring instrument we use for ascertaining the coordinates of an electron creates a disturbance in the latter's movement. That is why the more accurately we try to determine coordinates of the particles, the more uncertain becomes its speed.

It is impossible to gather accurate and complete information if the measuring instrument is comparable (by mass or energy) to the system being measured. 
Translation is a process of conveying information. Here too the instrument (the language into which the text is translated) is comparable to the system being measured (the language of the original).

When we convey the meaning of any component of the original, by so doing we create a disturbance in the system which "spoils" the meaning of the "complementary" component of the text.

The analysis of the measuring process in physics leads inevitably to wave mechanics, to the concept of the $\psi$-function.

The analysis of translation must inevitably lead to a wave theory of translation.

In this theory, the poem stops being a system with a full set of fixed quantities, and begins to be perceived as a "wave package" bearing the functional contents of the poem, its "message."

\section{THE NEEDLE'S EYE OF TRANSLATION}

One of the most crucial experiments in establishing the wave nature of electron consists in the following. An electron passes through the narrow hole in the screen " $Z$ " and is registred on the screen " $S$ " beyond it. We could expect our projectile to hit the target in the point " $O$ " lying directly on the line of its movement. Isn't it very natural?

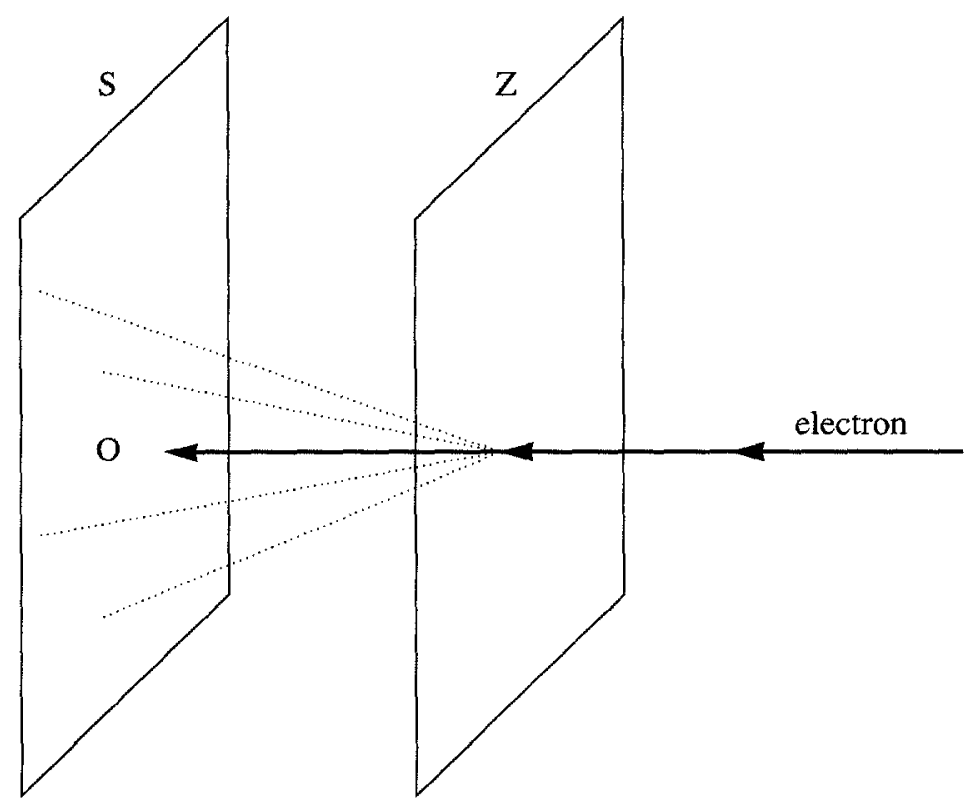

DIAGRAM 4

But the experiment shows that the electron can hit any point of the screen!

Only the probability of hitting one point or another is predictable.

The explanation is that the electron passing through the narrow hole fixes its coordinates in the plane of the screen, and thereby (according to the uncertainty relations) the transversal component of its momentum (and speed) becomes rather uncertain.

Similarly, while passing the needle's eye of translation, a poem can steer to the 
left or to the right, up or down. So translation proves to be an experiment confirming the wave nature of a poem. It is defined not by the full set of all the measurable quantities, not by the dry catalogue, but rather by its functional message (compare with $\psi$-function in quantum mechanics).

We have already stressed that the deep analogy between laws of translation and atomic physics is not accidental.

Physical interaction of particles on the hand, and translation on the other, may be considered as particular cases of the universal machanism of conveying information. Space rays (outcomes of space interactions) tell us about the processes occuring on stars, as the translated books about the processes in foreign literatures.

In both cases we observe the manifestation of universal informational laws.

Finely, we have to make clear the difference between poetry and prose. Our previous speculations are applicable mainly to poetry just as quantum laws to conventional, "classical" physics. This is contained in the uncertainty relation itself which includes (in its more exact form) the constant coefficient of Plank $\hbar$ and the mass $\mathrm{m}:$

$$
\Delta \mathrm{x} * \Delta \mathrm{p}=\frac{\hbar}{m}
$$

If the mass is big, $\Delta x * \Delta p \rightarrow 0$, and all the quantum effects vanish: a massive object behaves "classically," without quantum tricks.

Only in case of small masses we cannot do without quantum theory.

In translation the part of mass $m$ is performed by the quantity $\mu$ - the length of the least autonomous and regular fragment of the text. In verse it is a line, in prose it may be a chapter or the whole text.

If $\mu$ is small it means the text has a sort of atomic structure. This is the case with poetry. The shorter the line, the more clearly the poem's functional, wave nature manifests itself in translation.

Notes

1. The other two pillars are the theory of relativity (space-time continuum and Lorentz's reduction formula) and quantum mechanics (uncertainty relation). More on these later.

2. Critics sometimes speak of "poetical motif," "deep-seated structure," "conceptual information," etc. It is clear that they mean more or less the same.

3. Part of the energy that is lost presumably serves to increase the inner energy of the translator; or at least it should.

4. "And thank'd her for her courtesie" essentially is no less important a line since it adds a vital colour to the scene. Marshak masterfully compensates for the loss by inserting the word 4exnbdj4 ("with courtesy") into the third line. But this is another discussion: on methods of compensation.

\section{ANNEXE 1 - TIME-SPACE CONTINUUM IN THE THEORY OF TRANSLATION}

And so we have come to the theory of relativity. Its essence lies in the establishment of space-time relationships and laws for the restructuring of linear and temporal segments as the system of measurement changes. In other words, the theory of relativity provides a framework for the observation of any physical phenomenon.

The space-time relationship in poetical translation, unlike physics, is threedimensional, not four-dimensional. Each poem, generally speaking, has three coordinates: two spatial (geographical location) and one temporal (the date when the poem was written). Nothing should hinder us from reducing this, for clarity's sake, to a twodimensional model, where geographical location is expressed as a list of countries arranged in alphabetical order. After all, the map of poetry does not necessarily 
correspond exactly to the map of the world. For instance, Spain is closer to Chile than it is to England, at least in the 20th century.

Let us imagine an enormous display of books, where each shelf represents a century or a period in the history of poetry, and each section the various countries of the world: such is the model of a poetical space-time continuum.

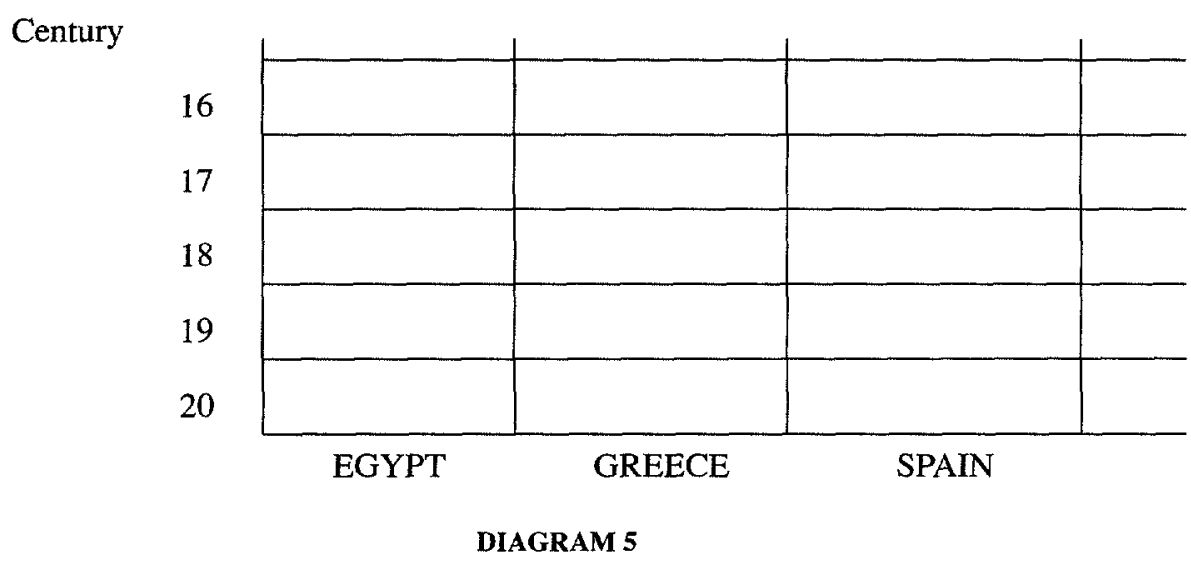

Suppose that on each shelf are original poetical works. Alongside, we place a display of their corresponding translations. The relationship between the two displays can be expressed by the formula:

$$
\mathrm{B}(x, y)=\mathrm{B}(\mathrm{A}(x, y))
$$

We now have to establish desirable laws of continuity for the translations. The function B must be topologically continuous in relation to the variables $x$ and $y$. This means, first of all, that the stylistic proximity between topologically near countries (such as Spain and Chile) must be sustained in the translation. It would be quite wrong for a translation of Chinese verse to be stylistically closer than Chilean to Spanish poetry. And secondly, temporal hierarchical relationships must be preserved. Ancient verse must on no account look more "modern" than modern verse.

\section{LORENTZ'S FORMULA}

Thus the location and period of the original must be taken into account when developing the correct style for the translation. We recommend an "aging" of a translation if the original poem is of a past century. But this does not mean that the translation of a 19th century poem necessarily has to be in 19th century language. Our difficulties would be insurmountable if we had to bind ourselves to this in translating, say, Latin poetry, let alone Ancient Egyptian. Even if we had a Russian language of the second millennium B.C. into which we could translate, I am much afraid that in our Soviet period no one would understand it.

Aging poetry is a necessary process, but whilst it must be consistent it should not be uniform, so as not to transgress the reader's comprehension threshold. See Diagram 5. 
$\mathbf{t}$ trans

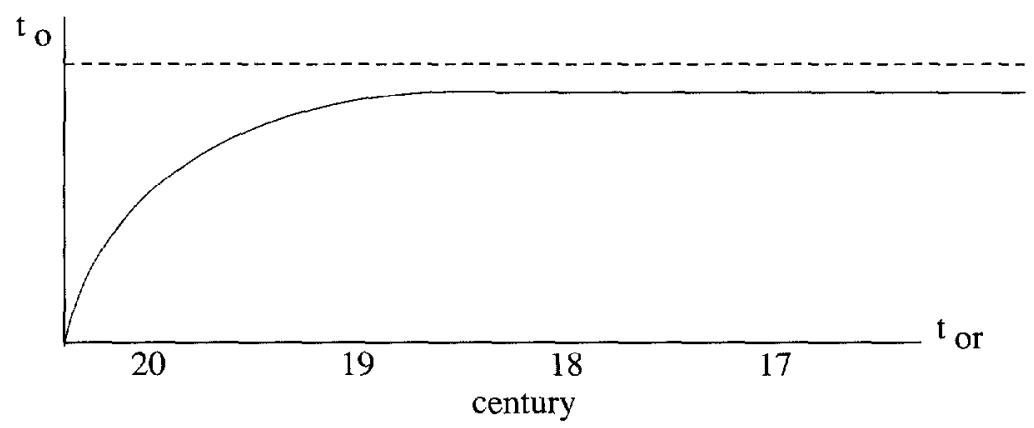

DIAGRAM 6

This curve is best rendered by the formula:

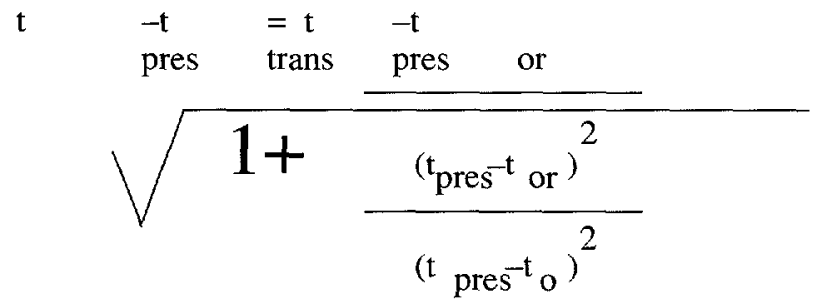

If the original is relatively modern and $t_{\text {pres }}$ is roughly equal to $t_{0}$, the poetry may be translated into the language of its period (the gradient of the curve); if the original is very ancient, and $t_{\text {trans }}$ is close to $t_{0}$, the poem should be translated into archaic language at the comprehension threshold.

The ideas outlined above may seem a little simplistic and even far-fetched; nevertheless they do serve their purpose: to highlight the fact that the language of translation reflects the "atavism" of the text, while at the same time reducing its datedness. In every poem, there exists a critical barrier beyond which it impossible to venture.

Such is Lorentz's law of time reduction as applied to translation. The formula here is very close to that found in the theory of relativity. There is a reason for this: the existence of unattainable thresholds. In the theory of relativity, the unattainable is the speed of light. In poetical translation, it is the comprehension threshold. 